\title{
Risk Factors of Graft-Versus-Host Disease in the Iranian Allogeneic Hematopoietic Stem Cell Transplantation: A 10-Year Experience
}

\author{
Mahshid Mehdizadeh ${ }^{1}$, Sayeh Parkhideh ${ }^{1}$, Sina Salari ${ }^{1}$, Elham Roshandel ${ }^{1}$, Mohammad Hosseïn Kazemi ${ }^{1}$, \\ Hossein Bonakchi ${ }^{1}$, Masoud Soleimani ${ }^{1} * \mathbb{D}$, Abbas Hajifathali $^{1} * \mathbb{( D}$ \\ Received: 6 Aug 2020 \\ Published: 2 Nov 2021
}

\section{Abstract}

Background: Graft-versus-host disease (GVHD) is a serious complication associated with allogeneic hematopoietic stem cell transplantation (allo-HSCT). Thus, it is necessary to evaluate the risk factors of GVHD in allo-HSCT. Herein, we studied the effects of some risk factors on GVHD incidence in patients with allo-HSCT.

Methods: We retrospectively evaluated the GVHD incidences and risk factors in 199 patients diagnosed with hematological disorders who underwent allo-HSCT in Taleghani hospital, Tehran, Iran, between 2007 and 2017. The univariable and multivariable analyses of time to event data were performed using the Logistic regression model. Computations were performed using SAS, and the level of statistical significance for univariable and multivariable analyses was set at $20 \%$ and $10 \%$, respectively.

Results: Acute GVHD (aGVHD) was seen in 59 (29.6\%) patients, and 18 (9\%) patients developed chronic GVHD (cGVHD). The odds of GVHD incidence in male to female transplants was 3.49 times greater than the male-to-male transplantations (CI, 1.16, 11.5; $\mathrm{p}<0.001$ ). The patients with body mass index (BMI) below 18.5 had $96 \%$ lower odds of GVHD incidence compared with those with BMI above 30 (CI, 0.007-0.27; $\mathrm{p}=0.013$ ). The odds of GVHD incidence in patients who were negative for cytomegalovirus (CMV) antigen was $76 \%$ lower than patients with positive CMV antigen (CI, 0.06-0.93; $\mathrm{p}=0.081$ ).

Conclusion: In a nutshell, our results indicated that the donor-recipient gender disparity, the recipient's BMI, and CMV infection/reactivation status might be pivotal risk factors, which should be taken into account for prevention and management of GVHD.

Keywords: Hematopoietic Stem Cell Transplantation, Graft-Versus-Host Disease, Body Mass Index, Cytomegalovirus

Conflicts of Interest: None declared
Funding: None

*This work has been published under CC BY-NC-SA 1.0 license.

Copyright $₫$ Iran University of Medical Sciences

Cite this article as: Mehdizadeh M, Parkhideh S, Salari S, Roshandel E, Kazemi MH, Bonakchi H, Soleimani M, Hajifathali A. Risk Factors of Graft-Versus-Host Disease in the Iranian Allogeneic Hematopoietic Stem Cell Transplantation: A 10-Year Experience. Med J Islam Repub Iran. 2021 (2 Nov);35:145. https://doi.org/10.47176/mjiri.35.145

\section{Introduction}

Allogeneic hematopoietic stem cell transplantation (allo-HSCT) is an important therapeutic choice for hematological disorders $(1,2)$. Graft-versus-host disease (GVHD), however, is a deadly consequence of allo-HSCT $(3,4)$. The

Corresponding author: Dr Abbas Hajifathali, hajifathali@yahoo.com

DrMasoud Samani, soleim_m@modares.ac.ir

1. Hematopoietic Stem Cell Research Center, Shahid Beheshti University of Medical Sciences, Tehran, Iran reported incidence of GVHD is $20 \%$ to $60 \%$ and the incidence ranges of acute GVHD (aGVHD) and chronic GVHD (cGVHD) is $30 \%$ to $50 \%$ and $30 \%$ to $70 \%$, respectively (5). The criteria of GVHD classification to acute

$\uparrow$ What is "already known" in this topic:

Graft-versus-host disease (GVHD) is a serious consequence of allogeneic hematopoietic stem cell transplantation (alloHSCT). The risk factors of GVHD are controversial and vary in different populations.

\section{$\rightarrow$ What this article adds:}

The 10-year experience from our HSCT center shows donorrecipient gender disparity, patients' BMI, and cytomegalovirus infection are risk factors of GVHD in allogeneic HSCT that should be taken into account for GVHD prevention and management. 
and chronic were previously based on the day of occurrence before or after 100 days post-HSCT, while the new classification criteria are based on the clinical manifestation (6-8). GVHD starts when the recipients' organs are attacked by donor T lymphocytes (9). Antigen presenting cells (APCs) are responsible for recognizing and presenting host-derived antigens and activating donor $\mathrm{T}$ lymphocytes for releasing the proinflammatory cytokines, including tumor-necrosis factor (TNF)- $\alpha$, interferon (IFN)- $\gamma$, interleukin (IL)-12, and IL-1, which lead to organ damage by immune cells (10-12). The most susceptible organs in GVHD are skin ( $81 \%$ of patients), gastrointestinal system $(54 \%)$, and liver $(50 \%)$. Their damages cause keratoconjunctivitis, oral mucositis, hepatic veno-occlusive disease, diarrhea, and hemorrhagic cystitis, with high mortality rate (11-14). The grades of acute and chronic GVHD, based on the severity of organ involvements, include grade I (mild), II (medium), III (severe), and IV (very severe) (14). The grades III and IV with the 5-year survival of $25 \%$ and $5 \%$, in that order, have poor prognosis (13). The treatment in high stages is irksome, hence, prevention is the best strategy.

Over the past 3 decades, many studies have identified various risk factors associated with GVHD, including (1) patient and donor age; (2) underlying disease; (3) donorrecipient relationship; (4) donor-recipient sex mismatch; (5) human leukocyte antigens (HLA) mismatch; (6) GVHD prophylaxis; (7) conditioning regimen; (8) total body irradiation (TBI); and (9) viral infections, such as cytomegalovirus (CMV) in the recipient or even in the donor (15-17).

The evaluation of GVHD risk factors is required in the HSCT recipient and donor on admission date. Some risk factors of GVHD had been defined by the National Institutes of Health consensus criteria (NCC) $(8,18)$; however, the evaluation of other risk factors and their relationship with GVHD could be more beneficial in prevention and management of the disease. In this study, we described the effect of some risk factors on GVHD incidence based on our 10-year experience in 199 allo-HSCT patients.

\section{Methods \\ Patients}

This retrospective study was performed on 199 patients (102 (51.3\%) men and 97 (48.7\%) women), with a mean age of $32.50 \pm 10.79$ years and various hematological disorders, who underwent allo-HSCT from 2007 to 2017 at the Hematopoietic Stem Cell Transplantation and Cell Therapy Center of Taleghani Hospital, Tehran, Iran. The study received the ethical approval from Shahid Beheshti University of Medical Sciences. The dataset for the analysis was extracted from the clinical records, and informed consent was obtained from all patients.

The studied hematological disorders mainly included acute myeloid leukemia (AML), acute lymphoblastic leukemia (ALL), non-Hodgkin's lymphoma (NHL), Hodgkin's disease (HD), and aplastic anemia (AA). All patients received allogeneic stem cell transplants, which are fully matched in HLA-A, -B, -C, -DRB1, and -DQB1 loci, except for 5 transplantations in which 1 locus was mis- matched. HLA typing was performed using the single specific primer-polymerase chain reaction (PCR-SSP) method (19). Patients were kept in isolated rooms with HEPA air filtration.

\section{Conditioning Regimen}

The myeloablative conditioning regimen was administered intravenously to all patients, which consisted of busulfan (BU; Otuska) $0.8 \mathrm{mg} / \mathrm{kg}$ every 6 hours for 4 days succeeded by 2 days of either cyclophosphamide (CY; Sandoz) $60 \mathrm{mg} / \mathrm{kg} /$ day or fludarabine (Flu; Genzyme) 30 $\mathrm{mg} / \mathrm{m}^{2}$ once a day for 5 days. Reduced Intensity Conditioning (RIC) regimen utilized for HD and NHL patients comprised fludarabine $30 \mathrm{mg} / \mathrm{m}^{2} \mathrm{IV}$ for 5 days, CCNU (Lomustine, Bristol Myers) $100 \mathrm{mg} / \mathrm{m}^{2}$ P.O. for 2 days and Melphalan (Alkeran; GlaxoSmithKline) $40 \mathrm{mg} / \mathrm{m}^{2} \mathrm{IV}$ for 1 day.

\section{Peripheral Blood Stem Cell Isolation}

Hematopoietic stem cells mobilization is induced in the donors using subcutaneous administration of 5 to $10 \mu \mathrm{g} / \mathrm{kg}$ granulocyte-colony stimulating factor (G-CSF) (filgrastim, Amgen) for 4 consecutive days. Then, peripheral blood stem cells were harvested using apheresis Spectra Optia (Terumo BCT, Lakewood). The $\mathrm{CD}^{+}$cells (FITCconjugated human anti-CD3, Beckman Coulter) and CD34 ${ }^{+}$cells (PE-conjugated human anti-CD34, EXBIO) were counted by flow cytometry (Attune NxT, Invitrogen). All patients received $5 \times 10^{8}$ and $2-4 \times 10^{6}$ mononuclear cells and $\mathrm{CD} 34^{+}$cells $/ \mathrm{kg}$, respectively.

\section{Neutropenia Phase Management}

All patients received prophylactic antibiotic drugs during the neutropenia phase, including oral acyclovir, fluconazole, and ciprofloxacin for viral, fungal, and bacterial infection. Intravenous imipenem and vancomycin for febrile neutropenia and metronidazole for intestinal infection were administered. Moreover, patients intravenously received G-CSF ( $5 \mu \mathrm{g} / \mathrm{kg} / \mathrm{day}$ ) from the day after transplantation until the day at which neutrophil counts reached-up to $1.5 \times 10^{9} / \mathrm{L}$.

\section{GVHD Prophylaxis and Diagnosis}

All patients received $3 \mathrm{mg} / \mathrm{kg} /$ day of cyclosporine A (CsA; Sandoz) intravenously between days -2 to +5 (The transplantation day was assumed as day zero) followed by $12.5 \mathrm{mg} / \mathrm{kg} /$ day P.O. for 6 months along with methotrexate (MTX; Sandoz) IV on days $+1(10 \mathrm{mg} / \mathrm{kg}),+3,+6$, and $+11(6 \mathrm{mg} / \mathrm{kg})$ as GVHD prophylaxis. Twenty patients received $2.5 \mathrm{mg} / \mathrm{kg}$ of anti-thymocyte globulin (ATG; Genzyme) for 2 days (-1 and -2$)$ in addition to the routine GVHD prophylaxis.

We applied the NCC system for the evaluation of GVHD incidence in allo-HSCT patients (7). The standard clinical signs, including diarrhea, rash, and abnormalities in liver function tests, along with biopsy and histopathological criteria in the involved organs, were principal manifestations for diagnosis of GVHD. Moreover, the CMV Ag were measured before and after the HSCT using real time PCR detection kit (Dynabio), and positive cases were 
detected according to the manufacturer's protocol. All patients with negative CMV Ag and IgM at the admission day underwent HSCT and included to the study.

\section{Risk Factors Evaluation}

In this study, some risk factors were evaluated in Iranian allo-HSCT patients including: (1) recipient and donor age; (2) disease diagnosis (categorized as AML, ALL, HD, NHL, AA, and other); (3) gender disparity between the donor and the recipient; (4) donor and recipient relationship; (5) recipient $\mathrm{ABO}$ blood group; (6) ABO incompatibility between the donor and the recipient; (7) complete and (8) partial remission; (9) human leukocyte antigens (HLA) mismatch; (10) BMI of the recipient; (11) GVHD prophylaxis strategies; (12) conditioning regimen; (13) receiving ATG in patients; and (14) cytomegalovirus antigen (CMV Ag) status of recipient. These risk factors are listed in Table 1.

\section{Statistical Analysis}

The univariable and multivariable analyses of GVHD incidence were performed using the logistic regression model. The Hosmer-Lemeshow test was used for the goodness-of-fit of our logistic model. The multivariable model was achieved through a backward selection method to find the risk factors with the highest prognosis. Computations were done using SAS Version 9.4 (SAS Institute Inc). The significance level for univariable and multivariable analyses was set at $20 \%$ and $10 \%$, respectively.

\section{Results}

\section{Patient Characteristics}

A total of 199 patients who had received allo-HSCT were included in the study. The donor-recipient gender combinations were 56 (28.1\%) male-male, 61(30.7\%) male-female, 32 (16.1\%) female-female, and 48(24.1\%) were female-male. The majority of the recipients 90 $(45.2 \%)$ had a BMI of 18.5-24.9. AML was the most prevailing among all kinds of disorders $((\mathrm{n}=100 ; 50.3 \%)$ followed by ALL $(\mathrm{n}=52 ; 26.1 \%)$, NHL $(\mathrm{n}=13 ; 6.5 \%)$, HD $(n=12 ;(6.1 \%)$, and AA $(n=8 ; 4 \%))$. Other less frequent diseases included adrenoleukodystrophy, myelodysplastic syndromes, and thalassemia were categorized as "other." Twenty patients $(10.1 \%)$ became positive for CMV Ag after HSCT. Most of the patients 148 (74.4\%) received grafts from sibling donors and 43 (21.6\%) patients received grafts from related donors. Only 5 recipients received mismatched HLA grafts, which were mismatched in 1 locus. The results revealed that type "O" was the most frequent blood group (31.2\%) closely followed by type "A" (30.7\%). According to the clinical manifestation, 59 (29.6\%) patients developed acute GvHD, while 18 (9\%) patients had chronic GVHD (Table 1).

\section{Univariate Analysis}

The risk factors, including donor-patient gender, recipient's BMI, recipient's CMV Ag, donor-recipient relationship, and blood group, were statistically significant on the incidence of GVHD. On the contrary, risk factors, such as
Table 1. Prognostic Factors Descriptive Analysis For Graft-VersusHost Disease

\begin{tabular}{|c|c|}
\hline Characteristics & Mean \pm SD/ Frequency $(\%)$ \\
\hline Recipient Age & $32.50 \pm 10.79$ \\
\hline Missing & $3(1.5 \%)$ \\
\hline Donor Age & $33.82 \pm 11.22$ \\
\hline Missing & $61(30.7 \%)$ \\
\hline \multicolumn{2}{|l|}{$\mathrm{DR}^{1}$ Gender } \\
\hline Male-Male & $56(28.1 \%)$ \\
\hline Male-Female & $61(30.7 \%)$ \\
\hline Female-Female & $32(16.1 \%)$ \\
\hline Female-Male & $48(24.1 \%)$ \\
\hline Missing & $2(1 \%)$ \\
\hline \multicolumn{2}{|l|}{ Recipient BMI } \\
\hline Below 18.5 & $34(17.1 \%)$ \\
\hline Between 18.5-24.9 & $71(35.5 \%)$ \\
\hline Between 25-29.9 & $49(24.6 \%)$ \\
\hline Above 30 & $32(16.3 \%)$ \\
\hline Missing & $13(6.5 \%)$ \\
\hline \multicolumn{2}{|l|}{ Diagnosed disease } \\
\hline NHL & $13(6.5 \%)$ \\
\hline $\mathrm{HD}$ & $12(6.1 \%)$ \\
\hline AML & $100(50.3 \%)$ \\
\hline ALL & $52(26.1 \%)$ \\
\hline Aplastic Anemia & $8(4 \%)$ \\
\hline Other & $6(3 \%)$ \\
\hline Missing & $8(4 \%)$ \\
\hline \multicolumn{2}{|l|}{ Recipient CMV Ag } \\
\hline Negative & $179(89.9 \%)$ \\
\hline Positive & $20(10.1 \%)$ \\
\hline Missing & $0(0 \%)$ \\
\hline \multicolumn{2}{|l|}{ Donor-recipient relationship } \\
\hline Sibling & $148(74.4 \%)$ \\
\hline Related & $43(21.6 \%)$ \\
\hline Missing & $8(4 \%)$ \\
\hline \multicolumn{2}{|l|}{ HLA } \\
\hline Match & $194(97.5 \%)$ \\
\hline Mismatch & $5(2.5 \%)$ \\
\hline Missing & $0(0 \%)$ \\
\hline \multicolumn{2}{|l|}{ Remission Status } \\
\hline CR1 & $112(56.3 \%)$ \\
\hline CR2 & $19(9.5 \%)$ \\
\hline CR3 & $4(2 \%)$ \\
\hline PR1 & $4(2 \%)$ \\
\hline PR2 & $9(4.5 \%)$ \\
\hline PR3 & $2(1 \%)$ \\
\hline PR4 & $3(1.6 \%)$ \\
\hline Missing & $46(23.1)$ \\
\hline \multicolumn{2}{|l|}{ ATG } \\
\hline Yes & $23(11.6 \%)$ \\
\hline No & $176(88.4 \%)$ \\
\hline Missing & $0(0 \%)$ \\
\hline \multicolumn{2}{|l|}{ Conditioning Regimen } \\
\hline $\mathrm{Bu} / \mathrm{Cy}$ & $108(54.3 \%)$ \\
\hline $\mathrm{Bu} / \mathrm{Fu}$ & $46(23.1 \%)$ \\
\hline $\mathrm{Bu} / \mathrm{Fu} / \mathrm{ATG}$ & $16(8 \%)$ \\
\hline RIC & $25(12.6 \%)$ \\
\hline Missing & $4(2 \%)$ \\
\hline \multicolumn{2}{|l|}{ Prophylaxis Regimen } \\
\hline $\mathrm{CSA}+\mathrm{MTX}$ & $179(89.9 \%)$ \\
\hline $\mathrm{CSA}+\mathrm{MTX}+\mathrm{ATG}$ & $20(10.1 \%)$ \\
\hline Missing & $0(0 \%)$ \\
\hline \multicolumn{2}{|l|}{ Recipient Blood Group } \\
\hline A & $61(30.7 \%)$ \\
\hline B & $42(21.1 \%)$ \\
\hline $\mathrm{AB}$ & $24(12 \%)$ \\
\hline $\mathrm{O}$ & $62(31.2 \%)$ \\
\hline Missing & $10(5 \%)$ \\
\hline Compatibility Blood Group & \\
\hline Compatible & $108(54.3 \%)$ \\
\hline Incompatible & $82(41.2 \%)$ \\
\hline Missing & $9(4.5 \%)$ \\
\hline GVHD Type & \\
\hline Acute & $59(29.6 \%)$ \\
\hline Chronic & $18(9 \%)$ \\
\hline No-GvHD & $122(61.4 \%)$ \\
\hline
\end{tabular}

${ }^{1 .}$ Donor-Recipient

the recipient and donor age, receiving ATG, conditioning, and prophylaxis regimen did not show any significance. The odds of GVHD incidence in male to female transplantations was $92 \%$ higher than the male-male HSCT (CI, 
$1.17,3.17 ; \mathrm{p}=0.069)$; however, the odds in female-female gender were $20 \%$ lower than male-male gender (CI, 0.43$1.50 ; \mathrm{p}=0.162)$. The BMI of the recipients below 18.5 had $58 \%$ lower odds of GVHD incidence compared with recipients with BMI above 30 (CI, 0.21-0.85; p=0.048). Conversely, BMI of the recipients between 18.5 and 24.9 had the odds of incidence $19 \%$ higher than recipients with
BMI above 30 (CI, 0.68-2.09; $\mathrm{p}=0.088$ ). The odds of recipients with negative $\mathrm{CMV} \mathrm{Ag}$ were $74 \%$ lower than patients with positive CMV Ag (CI, 0.11-0.60; $\mathrm{p}=0.033$ ). The odds of GVHD incidence in patients who received grafts from related donors was almost $45 \%$ lower than the patients who received grafts from sibling donors $(\mathrm{CI}$, $0.33-0.89 ; \mathrm{p}=0.109)$. The odds of GVHD incidence in

Table 2. Univariate and Multivariate Logistic Regression Models for Graft-Versus-Host Disease

\begin{tabular}{|c|c|c|c|c|}
\hline \multirow[b]{2}{*}{ Variable } & \multicolumn{2}{|c|}{ Univariate } & \multicolumn{2}{|l|}{ Multivariate } \\
\hline & Odds Ratio $(80 \% \mathrm{CI})$ & $\mathrm{p}$ & Adjusted Odds Ratio (90\% CI) & $\mathrm{p}$ \\
\hline Recipient Age & $0.99(0.97-1.008)$ & 0.465 & & \\
\hline Donor Age & $1.01(0.99-1.04)$ & 0.252 & & \\
\hline $\mathrm{DP}^{1}$ Gender & & $0.173^{*}$ & & $0.009^{* *}$ \\
\hline Female-Female & $0.80(0.43-1.50)$ & 0.162 & $0.11(0.011-0.64)$ & 0.033 \\
\hline Female-Male & $1.58(0.93-2.69)$ & 0.367 & $0.47(0.11-1.83)$ & 0.556 \\
\hline Male-Female & $1.92(1.17-3.17)$ & 0.069 & $3.49(1.16-11.50)$ & 0.001 \\
\hline Male-Male $\left(\mathrm{RL}^{1}\right)$ & - & - & - & - \\
\hline Recipient BMI & & $0.170^{*}$ & & $0.041^{* *}$ \\
\hline Below 18.5 & $0.42(0.21-0.85)$ & 0.048 & $0.04(0.007-0.27)$ & 0.013 \\
\hline Between 18.5-24.9 & $1.19(0.68-2.09)$ & 0.088 & $0.30(0.018-1.09)$ & 0.566 \\
\hline Between 25-29.9 & $0.83(0.45-1.51)$ & 0.91 & $0.25(0.016-0.94)$ & 0.908 \\
\hline Above $30\left(\mathrm{RL}^{1}\right)$ & - & - & - & - \\
\hline Diagnosed disease & & 0.912 & & \\
\hline NHL & $1.71(0.45-6.41)$ & 0.444 & & \\
\hline $\mathrm{HD}$ & $1.14(0.29-4.49)$ & 0.984 & & \\
\hline AML & $1.21(0.38-3.79)$ & 0.866 & & \\
\hline ALL & $1.51(0.47-4.87)$ & 0.420 & & \\
\hline Aplastic Anemia & $0.66(0.14-3.06)$ & 0.434 & & \\
\hline Other $\left(\mathrm{RL}^{1}\right)$ & - & - & & \\
\hline Recipient CMV Ag & & $0.033^{*}$ & & $0.081^{* *}$ \\
\hline Negative & $0.26(0.11-0.60)$ & 0.033 & $0.24(0.06-0.93)$ & 0.081 \\
\hline Positive $\left(\mathrm{RL}^{1}\right)$ & - & - & - & - \\
\hline Donor-recipient relationship & & $0.109^{*}$ & & $0.029^{* *}$ \\
\hline Related & $0.55(0.33-0.89)$ & 0.109 & $0.08(0.011-0.60)$ & 0.029 \\
\hline Sibling $\left(\mathrm{RL}^{1}\right)$ & - & - & - & - \\
\hline HLA & & 0.393 & & \\
\hline Match & $2.60(0.61-11.07)$ & 0.393 & & \\
\hline Mismatch $\left(\mathrm{RL}^{1}\right)$ & - & - & & \\
\hline Complete Remission & & 0.971 & & \\
\hline CR2 & $1.01(0.53-1.91)$ & 0.844 & & \\
\hline CR3 & $0.76(0.15-3.73)$ & 0.816 & & \\
\hline $\mathrm{CR} 1\left(\mathrm{RL}^{1}\right)$ & - & - & & \\
\hline Partial Remission & & 0.755 & & \\
\hline PR2 & $3.75(0.74-25.58)$ & 0.402 & & \\
\hline PR3 & $3(0.28-36.33)$ & 0.733 & & \\
\hline PR4 & $1.5(0.16-14.26)$ & 0.770 & & \\
\hline PR1 $\left(\mathrm{RL}^{1}\right)$ & - & - & & \\
\hline ATG & & 0.664 & & \\
\hline No & $1.22(0.67-2.22)$ & 0.664 & & \\
\hline Yes $\left(\mathrm{RL}^{1}\right)$ & - & - & & \\
\hline Conditioning Regimen & & 0.644 & & \\
\hline $\mathrm{Bu} / \mathrm{Cy}$ & $1.50(0.71-3.13)$ & 0.352 & & \\
\hline $\mathrm{Bu} / \mathrm{Fu}$ & $1.13(0.56-2.38)$ & 0.866 & & \\
\hline $\mathrm{Bu} / \mathrm{Fu} / \mathrm{ATG}$ & $1.45(0.34-2.01)$ & 0.558 & & \\
\hline $\operatorname{RIC}\left(\mathrm{RL}^{1}\right)$ & - & - & & \\
\hline Prophylaxis Regimen & & 0.955 & & \\
\hline $\mathrm{CSA}+\mathrm{MTX}$ & $0.97(0.51-1.82)$ & 0.955 & & \\
\hline $\mathrm{CSA}+\mathrm{MTX}+\mathrm{ATG}\left(\mathrm{RL}^{1}\right)$ & & & & \\
\hline Recipient Blood Group & & $0.170^{*}$ & & \\
\hline $\mathrm{A}$ & $2.1(1.29-3.39)$ & 0.048 & & \\
\hline $\mathrm{B}$ & $1.55(0.9-2.65)$ & 0.551 & & \\
\hline $\mathrm{AB}$ & $0.91(0.46-1.80)$ & 0.322 & & \\
\hline $\mathrm{O}\left(\mathrm{RL}^{1}\right)$ & - & - & & \\
\hline Compatibility Blood Group & & 0.588 & & \\
\hline Incompatible & $1.17(0.79-1.73)$ & 0.588 & & \\
\hline Compatible $\left(\mathrm{RL}^{1}\right)$ & - & - & & \\
\hline
\end{tabular}

${ }^{1 .}$ Reference Level

* Significant at 0.2

** Significant at 0.1 
patients who did not receive ATG were $22 \%$ higher than those who received ATG (CI, 0.67-2.22; $\mathrm{p}=0.664)$. Patients with blood group A have 2 times higher odds of GVHD incidence compared with those with blood group O (CI, 1.29-3.39; $\mathrm{p}=0.048)$. The patients with blood group $\mathrm{B}$ had the odds of incidence, which was $55 \%$ higher than patients with blood group $\mathrm{O}(\mathrm{CI}, 0.9-2.65 ; \mathrm{p}=0.551)$. The patients with type $\mathrm{AB}$ had $9 \%$ lower odds of incidence compared with type $\mathrm{O}$ patients (CI, 0.46-1.80; $\mathrm{p}=0.322$ ) (Table 2).

\section{Multivariate Analysis}

The result of the Hosmer-Lemeshow test indicated that our model was valid. In this multivariable model, donorpatient gender, recipient BMI, CMV Ag, and donorrecipient relationship were presented as influential risk factors. Assuming that the effects of all the other factors were constant, for male-female gender, the odds of GVHD incidence was 3.49 times higher than male-male gender (CI, 1.16-11.5; $\mathrm{p}=0.001$ ). The odds of GVHD incidence in female-female was $89 \%$ lower than male-male (CI, 0.01 $0.64 ; \mathrm{p}=0.033)$. The recipients with BMI below 18.5 had the odds of GVHD incidence $96 \%$ lower than recipients with BMI above 30 (CI, 0.007-0.27; $\mathrm{p}=0.013$ ). The odds of GVHD incidence in recipients with negative CMV Ag was $76 \%$ lower than patients with positive CMV Ag (CI, $0.06-0.93 ; p=0.081)$. The patients who received grafts from related donors had the odds of GVHD incidence, which was $92 \%$ lower than the patients who received grafts from sibling donors (CI, 0.01-0.60; $\mathrm{p}=0.029)$ (Table 2).

As shown in Table 3, $29(47.5 \%)$ of the male-female and $9(28.1 \%)$ of female-female transplantations developed GVHD. The number of male-male transplantation was $18(32.2 \%)$. The BMI of the recipients with GVHD incidence below 18.5 was the least frequent $8(23.5 \%)$ compared with the recipients with BMI above 30, which were $14(43.75 \%)$. Among the recipients with positive CMV Ag, 11 (55\%) and with negative CMV Ag, 70 (39.1\%) patients developed GVHD. A total of 64 $(43.25 \%)$ of the patients who had GVHD incidence received a graft from sibling donors compared with the ones who received a graft from related donors, which were 13
$(30.23 \%)$

\section{Discussion}

Despite all benefits of allo-HSCT for malignancy patients, this treatment is confined by high morbidity and mortality arising from GVHD $(9,20,21)$. The aim of this research was to explain the influential risk factors that lead to GVHD incidence based on a 10-year recorded data of a single center in Iran. This was a relatively large study with a decent follow-up period and small attrition. In our study, aGVHD was observed in 59 (29.6\%) patients and 9 (18\%) of our patients developed cGVHD. Previous studies have reported the recipient, donor age, and donor-recipient gender as crucial risk factors for incidence of GVHD in allo-HSCT $(22,23)$. Our results have revealed that recipient and donor age were not significantly related to GVHD incidence. This is consistent with the study of Jagasia et al, which illustrated that recipient and donor age did not have any effect on aGVHD incidence (15). However, it has been shown that the donor-recipient gender is a significant factor for GVHD incidence. In this study, transplants from male donors to female recipients were associated with increased incidence of GVHD. Countering that, the female recipients who received transplants from females had lower GVHD incidence (24). It could be interpreted that the gender parity of donor and recipient might decrease the probability of GVHD. AW Loren et al have found that parity of the donor does not have an impact on the occurrence of acute GVHD and overall survival; nevertheless, it increases the incidence of chronic GVHD (25). One of the challenging contradictions between our results and several previous findings is that they have mentioned that GVHD incidence in female to male transplantations was significantly greater than the reverse combination (26-28).

Among the many risk factors for GVHD incidence and mortality after allo-HSCT, HLA compatibility is a pivotal criterion (29). HLA-identical sibling is the best standard source for allo-HSCT, but some patients do not have any HLA-identical sibling, and inevitably need grafts from a matched related (MRD)/unrelated donor (MUD) (30). Our result demonstrated that the GVHD incidence in patients who received grafts from related donors was significantly

\begin{tabular}{lcc} 
Table 3. Distribution of frequency of risk factors in final multivariable logistic model by GVHD status & GVHD = No (Frequency/\%) \\
\hline Variable & GVHD $=$ Yes (Frequency/\%) & $23(71.9 \%)$ \\
\hline D-P Gender & $9(28.1 \%)$ & $33(68.75 \%)$ \\
Female-Female & $15(31.25 \%)$ & $32(52.5 \%)$ \\
Female-Male & $29(47.5 \%)$ & $38(67.8 \%)$ \\
Male-Female & $18(32.2 \%)$ & $26(76.5 \%)$ \\
Male-Male & & $41(57.75 \%)$ \\
Recipient BMI & $8(23.5 \%)$ & $30(61.3 \%)$ \\
Below 18.5 & $30(42.25 \%)$ & $18(56.25 \%)$ \\
18.5-24.9 & $19(38.7 \%)$ & $9(45 \%)$ \\
$25-29.9$ & $14(43.75 \%)$ & $109(60.9 \%)$ \\
Upper 30 & $11(55 \%)$ & $84(56.75 \%)$ \\
Recipient CMV Ag & $70(39.1 \%)$ & $30(69.77 \%)$ \\
Positive & & \\
Negative & $64(43.25 \%)$ & \\
Donor-recipient relationship & $13(30.23 \%)$ & \\
Sibling & & \\
Related & &
\end{tabular}


lower than patients who received grafts from sibling donors. These data collected from patients whose HLA compatibility in sibling and MRD transplantations were $6 / 6$ matched (HLA-A, -B, and -DRB1 loci) and 10/10 matched (HLA-A -B, -C, -DRB1, and -DQB loci), respectively. Hence, regarding the difference in HLA evaluation of sibling and MRD transplantations, this significant difference is not clinically valuable.

There are proinflammatory cytokines, such as TNF- $\alpha$, IL-1 $\beta$, and IL-6, in obese people, defined with $\mathrm{BMI} \geq 30 \mathrm{~kg} / \mathrm{m}^{2}$ of body surface, and overweight people (BMI, 25-29.9 kg/m²) (31). On that account, BMI index in recipients can be considered as a risk factor for GVHD prognosis. In our results, it has been observed that recipients with $\mathrm{BMI} \leq 18.5 \mathrm{~kg} / \mathrm{m}^{2}$, compared with recipients with obese ones, manifested much lower GVHD incidence. In addition to the more inflammatory factors in obese patients, the lower absorption of GVHD prophylaxis medications in overweight patients might be one of the explanations for higher rate of GVHD in obese recipients. However, Lucie $\mathrm{M}$ et al found no relationship between the recipient BMI index and incidence of GVHD (32).

Recent studies presented that the CMV replication is a risk factor for GVHD; however, this finding is still controversial $(33,34)$. The result of the current study revealed that the GVHD incidence in recipients whose CMV Ag is negative is significantly lower than patients with positive CMV Ag. Accordingly, CMV infection in a recipient could be a main factor for an initial phase of the GVHD. Our result is in line with the study of N. Cantoni et al that reported CMV replication as a risk factor for aGVHD incidence (35).

Conditioning regimen can cause tissue damage and activation of recipients' APCs leading to inflammation and GVHD incidence $(36,37)$. No significant difference was found in the incidence of GVHD among the different conditioning regimens. Furthermore, the patients who were given $\mathrm{Bu} / \mathrm{Cy}, \mathrm{Bu} / \mathrm{Fu}$, and $\mathrm{Bu} / \mathrm{Fu} / \mathrm{ATG}$ had a higher $\mathrm{GVHD}$ incidence compared with those who received RIC regimen, but it was not significant. These results are consistent with what have been reported by $\mathrm{H}$ Nakasone et al in which TBI is a significant risk factor for GVHD incidence, and there is no significant difference in myeloablative conditioning and RIC regimen (38). Ergo, the impact of the conditioning regimen intensity, and GVHD prophylaxis on GVHD incidence should be considered according to the patient physiology and background of patients. Having said that, it is still a matter of debate (39). As the preceding studies indicated, the use of prophylaxis drugs, such as cyclosporine that inhibits regulatory $\mathrm{T}$ cells, with short-term MTX decreased the incidence of acute GVHD $(40,41)$. In this study, this prophylaxis was utilized for allogeneic patients, and the difference in the incidence of GVHD was analyzed when CSA+MTX was used with or without ATG. The administration of ATG was not an influential prognostic factor for the decrement of GVHD incidence in transplant. This result is in contrast with the report of Redondo Velao et al who found that aGvHD incidence and toxicity have been lower in ATG-based prophylaxis (42). The controversy might be due to the small sample size of patients who received ATG in our study.

The blood group A compared with blood group $\mathrm{O}$ was an adverse prognostic factor for the incidence of GVHD. Contrastingly, there was no significant relationship between the donor-recipient ABO blood group incompatibility status and the incidence of GVHD. This result is in agreement with the study of Seebach JD et al that found no impact of ABO blood group incompatibility on outcomes of allo-HSCT (43). The most important limitation of the study is that this report was obtained from a single center. A multi-center study is highly suggested for more reliable results, especially for controversial findings. The data on disease relapse and survival of the patients was not included in the study because of incomplete documentation.

\section{Conclusion}

In summary, we report the risk factors, including donorpatient gender, recipient's BMI, recipient's CMV infection, were statistically significant on the incidence of GVHD. The results of this study can help a more rational choice of recipient's background, donor character, and treatment strategies to improve outcomes after allo-HCT.

\section{Acknowledgment}

The authors would like to express their sincere gratitude to the head and staff of the Hematopoietic Stem Cell Research Center, Shahid Beheshti University of Medical Sciences, Tehran, Iran, for their kind assistance in conducting the study.

\section{Conflict of Interests}

The authors declare that they have no competing interests.

\section{References}

1. Ardakani MT, Mehrpooya M, Mehdizadeh M, Beiraghi N, Hajifathali A, Kazemi MH. Sertraline treatment decreased the serum levels of interleukin-6 and high-sensitivity C--reactive protein in hematopoietic stem cell transplantation patients with depression; a randomized double-blind, placebo-controlled clinical trial. Bone Marrow Transplant. 2020;55(4):830-2.

2. Hajifathali A, Parkhideh S, Kazemi MH, Chegeni R, Roshandel E, Gholizadeh M. Immune checkpoints in hematologic malignancies: What made the immune cells and clinicians exhausted! J Cell Physiol. 2020;235(12):9080-97.

3. Ghasemi K, Parkhideh S, Kazemi MH, Salimi M, Salari S, Nalini R, et al. The role of serum uric acid in the prediction of graft-versus-host disease in allogeneic hematopoietic stem cell transplantation. J Clin Lab Anal. 2020:e23271.

4. Ghavamzadeh A, Alimoghaddam K, Ghaffari F, Derakhshandeh R, Jalali A, Jahani M. Twenty years of experience on stem cell transplantation in Iran. Iran Red Crescent Med J. 2013;15(2):93.

5. Boyiadzis M, Arora M, Klein JP, Hassebroek A, Hemmer M, UrbanoIspizua $\mathrm{A}$, et al. Impact of chronic graft-versus-host disease on late relapse and survival on 7,489 patients after myeloablative allogeneic hematopoietic cell transplantation for leukemia. Clin Cancer Res. 2015;21(9):2020-8.

6. Ghimire S, Weber D, Mavin E, Dickinson AM, Holler E. Pathophysiology of GvHD and other HSCT-related major complications. Front Immunol. 2017;8:79.

7. Jagasia MH, Greinix HT, Arora M, Williams KM, Wolff D, Cowen EW, et al. National Institutes of Health consensus development project on criteria for clinical trials in chronic graft-versus-host disease: I. The 
2014 Diagnosis and Staging Working Group report. Biol Blood Marrow Transplant. 2015;21(3):389-401. e1.

8. Filipovich AH, Weisdorf D, Pavletic S, Socie G, Wingard JR, Lee SJ, et al. National Institutes of Health consensus development project on criteria for clinical trials in chronic graft-versus-host disease: I. Diagnosis and staging working group report. Biol Blood Marrow Transplant. 2005;11(12):945-56.

9. Sung AD, Chao NJ. Concise review: acute graft-versus-host disease: immunobiology, prevention, and treatment. Stem Cells Transl Med. 2013;2(1):25-32.

10. Das R, Chen X, Komorowski R, Hessner MJ, Drobyski WR. Interleukin-23 secretion by donor antigen-presenting cells is critical for organ-specific pathology in graft-versus-host disease. Blood. 2009;113(10):2352-62.

11. Ferrara JL, Levine JE, Reddy P, Holler E. Graft-versus-host disease. Lancet. 2009;373(9674): 1550-61.

12. Bakhshaei P, Kazemi MH, Golara M, Abdolmaleki S, KhosraviEghbal R, Khoshnoodi J, et al. Investigation of the cellular immune response to recombinant fragments of filamentous hemagglutinin and pertactin of Bordetella pertussis in BALB/c mice. J Interferon Cytokine Res. 2018;38(4):161-70.

13. Cahn JY, Klein JP, Lee SJ, Milpied N, Blaise D, Antin JH, et al. Prospective evaluation of 2 acute graft-versus-host (GVHD) grading systems: a joint Societe Francaise de Greffe de Moelle et Therapie Cellulaire (SFGM-TC), Dana Farber Cancer Institute (DFCI), and International Bone Marrow Transplant Registry (IBMTR) prospective study. Blood. 2005;106(4):1495-500.

14. Choi SW, Levine JE, Ferrara JL. Pathogenesis and management of graft-versus-host disease. Immunol Allergy Clin. 2010;30(1):75-101.

15. Jagasia M, Arora M, Flowers ME, Chao NJ, McCarthy PL, Cutler $\mathrm{CS}$, et al. Risk factors for acute GVHD and survival after hematopoietic cell transplantation. Blood. 2012;119(1):296-307.

16. Landgren O, Gilbert ES, Rizzo JD, Socié G, Banks PM, Sobocinski $\mathrm{KA}$, et al. Risk factors for lymphoproliferative disorders after allogeneic hematopoietic cell transplantation. Blood. 2009;113(20):4992-5001.

17. Saliba RM, de Lima M, Giralt S, Andersson B, Khouri IF, Hosing C, et al. Hyperacute GVHD: risk factors, outcomes, and clinical implications. Blood. 2007;109(7):2751-8.

18. Flowers ME, Inamoto Y, Carpenter PA, Lee SJ, Kiem H-P, Petersdorf EW, et al. Comparative analysis of risk factors for acute graft-versus-host disease and for chronic graft-versus-host disease according to National Institutes of Health consensus criteria. Blood. 2011;117(11):3214-9.

19. Dunckley H. HLA typing by SSO and SSP methods. Immunogenetics. 2012:9-25.

20. Smith SR, Haig AJ, Couriel DR. Musculoskeletal, neurologic, and cardiopulmonary aspects of physical rehabilitation in patients with chronic graft-versus-host disease. Biol Blood Marrow Transplant. 2015;21(5):799-808.

21. Momeni-Varposhti Z, Kazemi MH, Talebi M, Chegeni R, Roshandel E, Hajifathali A, et al. Plasma levels of norepinephrine and expression levels of 32 -adrenergic receptor gene correlate with the incidence of acute graft-versus-host disease. Med J Islam Repub Iran. 2020;34:151.

22. Hajifathali A, Parkhideh S, Mehdizadeh M, Karami S, Roshandel E, Bonakchi $\mathrm{H}$. Donor and recipient individual factors as predictive markers of overall survival after allogeneic hematopoietic stem cell transplantation; Dream or Reality. Acta Med Iran. 2021:28-36.

23. Rauofi A, Hajifathali A, Karami S, Tavakoli F, Elham R, Bonakchi $\mathrm{H}$, et al. The apheresis content analysis in Allo-HSCT represents reliable influential factors on graft-versus-host disease and overall survival. Transfus Apher. 2020:103009.

24. Lehners N, Schwarzbich MA, Schmidt K, Puthenparambil J, Radujkovic A, Dietrich S, et al. Female Donors Are Associated with an Increased Risk of Chronic Graft-Versus-Host Disease (cGVHD) Independent of Recipient Sex but Provide Superior Graft-VersusLeukemia Activity Once cGVHD Is Established. Am Soc Hematol. 2014.

25. Loren AW, Bunin GR, Boudreau C, Champlin RE, Cnaan A, Horowitz MM, et al. Impact of donor and recipient sex and parity on outcomes of HLA-identical sibling allogeneic hematopoietic stem cell transplantation. Biol Blood Marrow Transplant. 2006;12(7):758-69.

26. van Halteren AG, Dierselhuis MP, Netelenbos T, Fechter M. Donor parity no longer a barrier for female-to-male hematopoietic stem cell transplantation. Chimerism. 2014;5(2):56-8.
27. Friedrich P, Guerra-García P, Stetson A, Duncan C, Lehmann L. Young female donors do not increase the risk of graft-versus-host disease or impact overall outcomes in pediatric HLA-matched sibling hematopoietic stem cell transpllantation. Biol Blood Marrow Transplant. 2018;24(1):96-102.

28. Kim HT, Zhang M-J, Woolfrey AEE, Martin AS, Chen J, Saber W, et al. Donor and recipient sex in allogeneic stem cell transplantation: what really matters. Haematologica. 2016;101(10):1260-6.

29. Petersdorf EW. Genetics of graft-versus-host disease: the major histocompatibility complex. Blood Rev. 2013;27(1):1-12.

30. Tiercy J-M. How to select the best available related or unrelated donor of hematopoietic stem cells? Haematologica. 2016;101(6):6807.

31. Weisberg SP, McCann D, Desai M, Rosenbaum M, Leibel RL, Ferrante AW, Jr. Obesity is associated with macrophage accumulation in adipose tissue. J Clin Invest. 2003;112(12):1796-808.

32. Turcotte LM, Wang T, Hemmer MT, Spellman SR, Arora M, Couriel D, et al. Donor body mass index does not predict graft versus host disease following hematopoietic cell transplantation. Bone Marrow Transplant. 2018;53(7):932-7.

33. Mardani M, Abolghasemi S, Shabani S, Tavakoli F, Saeedi A, Parkhideh $\mathrm{S}$, et al. The association of conditioning regimen with cytomegalovirus reactivation after allogeneic hematopoietic stem cell transplantation. Iran J Microbiol. 2020.

34. Cho SY, Lee DG, Kim HJ. Cytomegalovirus infections after hematopoietic stem cell transplantation: current status and future immunotherapy. Int J Mol Sci. 2019;;20(11):2666.

35. Cantoni N, Hirsch HH, Khanna N, Gerull S, Buser A, Bucher C, et al. Evidence for a bidirectional relationship between cytomegalovirus replication and acute graft-versus-host disease. Biol Blood Marrow Transplant. 2010;16(9):1309-14.

36. van Balen $P$, van der Zouwen $\mathbb{B}$, Kruisselbrink AB, Eefting $M$, Szuhai K, Jordanova ES, et al. Tissue Damage Caused by Myeloablative, but Not Non-Myeloablative, Conditioning before Allogeneic Stem Cell Transplantation Results in Dermal Macrophage Recruitment without Active T-Cell Interaction. Front Immunol. 2018;9:331.

37. Gholami MD, Falak R, Heidari S, Khoshmirsafa M, Kazemi MH, Zarnani A-H, et al. A truncated snaill transcription factor alters the expression of essential EMT markers and suppresses tumor cell migration in a human lung cancer cell line. Recent Pat Anticancer Drug Discov. 2019;14(2):158-69.

38. Nakasone H, Fukuda T, Kanda J, Mori T, Yano S, Kobayashi T, et al. Impact of conditioning intensity and TBI on acute GVHD after hematopoietic cell transplantation. Bone Marrow Transplant. 2015;50(4):559-65.

39. Mohty M, Malard F, Savani BN. High-dose total body irradiation and myeloablative conditioning before allogeneic hematopoietic cell transplantation: time to rethink? Biol Blood Marrow Transplant. 2015;21(4):620-4.

40. Hashmi K, Khan B, Ahmed P, Hussain I, Altaf C, Raza S, et al Graft versus host disease in allogeneic stem cell transplantation-3 1/2 years experience. J Pak Med Assoc. 2005;55(10):423.

41. Onishi Y, Mori T, Yamazaki H, Takenaka K, Yamaguchi H, Shingai $\mathrm{N}$, et al. Cyclosporine/methotrexate versus tacrolimus/methotrexate with or without anti-thymocyte globulin as GVHD prophylaxis in adult patients with aplastic anemia. Ann Hematol. 2021;100(1):21728.

42. Velao SR, Kwon M, Champ D, Cascon MP, Balsalobre P, Diez J, et al. Antithymocyte Globulin-Based Prophylaxis for Graft Versus Host Disease Compared to Post-Transplant Cyclophosphamide-Based Prophylaxis in Matched Unrelated Donor Transplantation. Am Soc Hematol. 2016.

43. Seebach JD, Stussi G, Passweg JR, Loberiza FR, Jr., Gajewski JL, Keating A, et al. ABO blood group barrier in allogeneic bone marrow transplantation revisited. Biol Blood Marrow Transplant. 2005;11(12):1006-13. 